\title{
Percepção de Justiça e Reações Retaliatórias nas Organizações: Análise Empírica de um Modelo Atitudinal
}

\author{
Helenides Mendonça \\ Alvaro Tamayo
}

\section{Resumo}

Este estudo foi desenvolvido com o objetivo de testar um modelo teórico de estimativa da atitude em relação à retaliação. Participaram da pesquisa 313 empregados de uma instituição pública. Para testar a estrutura teórica hipotetizada sobre o fenômeno, foi aplicada a técnica estatística modelagem de equação estrutural. Dois conjuntos de resultados foram analisados: o ajuste global do modelo teórico hipotetizado e a estimativa da magnitude do efeito dos construtos sobre as variáveis mensuradas. Os coeficientes de ajuste do modelo foram estatisticamente significativos, indicando adequação dos pressupostos teóricos. A respeito da estimativa das relações entre as variáveis, os resultados indicam que o modelo teórico proposto é adequado e explica $81 \%$ da atitude em relação à retaliação. Estes resultados foram discutidos, adotando-se duas vertentes: uma que discute a adequação em utilizar medidas atitudinais em relação à retaliação, e a outra que aponta o contexto organizacional como o principal responsável pelo critério atitudinal.

Palavras-chaves: percepção de justiça; retaliação organizacional; modelo atitudinal.

\begin{abstract}
This study was developed aiming to test a theoretical model to estimate the attitude in relation to retaliation. There were 313 employees of a public institution participating in this research. In order to test the theoretical structure hypothesized about the phenomenon, the statistical technique modeling of structural equation was applied. Two sets of results were analyzed: the global adjustment of the theoretical model hypothesized and the estimate of the construct effect magnitude upon the variables measured. The model adjustment coefficients were statistically significant, indicating suitability of the theoretical assumptions. As to the estimate of the relations among the variables, the results indicate that the theoretical model proposed is suitable and it explains $81 \%$ of the attitude in relation to retaliation. These results were discussed based on two currents: one that discusses the suitability of using attitude measures in relation to retaliation, and the other that points out the organizational context as the main responsible for attitude criterion.
\end{abstract}

Key words: perception of justice; organizational retaliation; attitude model. 


\section{INTRODUÇÃO}

À luz dos debates sobre direitos humanos e das concepções que defendem o fim das injustiças sociais, das discriminações e da violência interpessoal no local de trabalho, torna-se primordial que pesquisadores interessados em comportamento organizacional direcionem seus estudos com o objetivo de compreender as causas e as conseqüências dos comportamentos bem aceitos no sistema organizacional. No entanto é também fundamental que se estudem os comportamentos de retaliação no trabalho, pois são grandes os prejuízos causados com sua emissão.

Comumente, a retaliação pode ser definida com diferentes sentidos: represália, desforra ou desagravo. De acordo com Houaiss e Villar (2001, p. 2444), retaliação é o "ato ou efeito de revidar com dano igual ao sofrido" e significa o mesmo que a aplicação da pena de talião, que é "qualquer vingança em proporção igual ou considerada equivalente ao mal sofrido" (Houaiss e Villar, 2001, p. 2662). O conceito clássico de retaliação refere-se, portanto, à lei de talião, o antigo ditado popular do olho por olho, dente por dente, que significa a revanche, isto é, aqui se faz, aqui se paga.

Os estudos empíricos na área das Ciências Organizacionais têm negligenciado os comportamentos de retaliação. Apenas na última década começaram a surgir, de maneira incipiente, os primeiros trabalhos sobre esses comportamentos. Na literatura especializada podem ser encontrados diversos estudos sobre a injustiça no trabalho, mas poucos sobre as ações retaliatórias emitidas no contexto organizacional, quando o trabalhador vivencia a experiência da injustiça.

Uma revisão bibliográfica sistemática mostra que existe grande desproporção quantitativa entre as pesquisas empíricas, que investigam os comportamentos considerados socialmente inadequados dos empregados nas empresas, e a ênfase dada aos fenômenos desejáveis do comportamento organizacional, tais como comportamento de cidadania organizacional (Moorman, 1991; Organ e Moorman, 1993; Siqueira, 1995), comprometimento (Mowday, Steers e Porter, 1979; BorgesAndrade, Afanasieff e Silva, 1989; Tamayo et al., 2001) e satisfação no trabalho (Tamayo, 1998).

Dados levantados por Robinson e Bennett (1995), nos Estados Unidos, mostram que os comportamentos socialmente inadequados dos empregados provocam 
perda estimada de 6 a 200 bilhões de dólares anualmente. Além disso, os referidos autores estimam que de 33\% a 75\% dos empregados se engajam em pelo menos um dos seguintes comportamentos: roubo, fraude, desvio de dinheiro, vandalismo, sabotagem, absenteísmo e agressão.

No Brasil não se conhece nenhum estudo descritivo sobre os desvios de comportamento no local de trabalho, apesar de ser de conhecimento geral que os custos advindos de atitudes retaliatórias no trabalho são altíssimos para as organizações. A prevalência de desvios comportamentais no local de trabalho, aliada aos conseqüentes prejuízos organizacionais, mostra a necessidade de desenvolvimento de programas de pesquisa que enfoquem, de maneira específica, sistemática e teórica, a análise de tais comportamentos.

A retaliação pode ocorrer em diferentes contextos, abrangendo relações interpessoais, organizacionais e até mesmo societais. No contexto sociopolítico, a retaliação pode ocorrer de maneira sutil, dificultando importação e exportação de produtos ou, de maneira explícita, pelo rompimento de relações diplomáticas e até mesmo por meio de ataques violentos a uma nação. Esse é o caso da resposta americana aos atentados terroristas ocorridos no dia 11 de setembro de 2001, que derrubaram as duas torres gêmeas do World Trade Center em Nova York. No contexto organizacional, a retaliação tem sido definida como resposta às experiências de injustiça vivenciadas pelos trabalhadores.

O presente estudo considera que a retaliação pode ocorrer de maneira explícita (flagrante) ou sutil, podendo causar danos psicológicos ou físicos.

E em termos do contexto organizacional? Pode-se afirmar que nas organizações as pessoas seguem a lei do olho por olho, dente por dente? Ou a retaliação no trabalho tem características peculiares e específicas para esse contexto? A retaliação ocorre em resposta às injustiças percebidas no ambiente de trabalho?

Com base nessas questões, o presente estudo busca discutir os principais trabalhos encontrados na literatura sobre retaliação, estabelecer um debate acerca do impacto da justiça sobre o funcionamento organizacional e sobre os comportamentos e as atitudes dos empregados e apresentar os resultados de uma investigação empírica que testa um modelo atitudinal da retaliação organizacional.

O principal objetivo deste estudo é testar um modelo atitudinal de estimativa da retaliação, visando a analisar como as variáveis antecedentes, que são a percepção de justiça organizacional e a percepção e o julgamento acerca da retaliação, explicam a variável-critério, que é a atitude em relação à retaliação. 


\section{Estudos sobre Retaliação Organizacional}

Atualmente, apesar de muito incipientes, os estudos sobre os comportamentos negativos dos empregados têm emergido em contrapartida às pesquisas sobre cidadania organizacional. Skarlicki e Folger (1997), pioneiros na investigação do comportamento de retaliação organizacional, pressupõem que esses comportamentos aumentaram em resposta à injustiça percebida. Esses autores defendem a necessidade de que as pesquisas enfoquem os efeitos da interação de justiça distributiva, de procedimentos e interacional como preditores dos comportamentos disfuncionais na organização, estabelecendo como hipóteses: justiça interacional e de distribuição interagem para predizer retaliação; apenas em baixo nível de justiça interacional a justiça de procedimentos modera até que ponto as variações na justiça distributiva predizem se a retaliação contra a organização ocorrerá; apenas em baixo nível de justiça de procedimentos a justiça interacional modera a relação entre justiça distributiva e comportamento de retaliação.

Buscando verificar como essas formas de justiça interagem umas com as outras para predizer o comportamento de retaliação organizacional (CRO), Skarlicki e Folger (1997) realizaram um estudo que enfoca os comportamentos negativos utilizados pelos empregados para punir a organização e seus representantes em resposta às injustiças percebidas. Foi utilizada a técnica dos incidentes críticos (Flanagan, 1954) para levantar os itens da escala de observação comportamental, solicitando-se a dois grupos independentes, de sete membros cada, todos sujeitos com experiência no trabalho, que identificassem comportamentos que poderiam ser definidos como de retaliação na organização. Antes de os sujeitos serem questionados, foi-lhes entregue a seguinte descrição dos comportamentos de retaliação organizacional: Pesquisas sugerem que quando as pessoas percebem que têm sido tratadas injustamente no trabalho tendem a encontrar formas de contra-atacar e descontar. Esta retaliação pode ser direta ou indireta e pode ser direcionada à organização ou a alguém dentro da organização. Aos sujeitos foi solicitado que trouxessem exemplos de CRO que tivessem observado nos últimos 6-12 meses. Especificamente: o que a pessoa fez que pode ser considerado como retaliação? Por que ele considerou esse exemplo como retaliação? Cada sujeito contribuiu com, no máximo, cinco incidentes. Um total de 27 incidentes diferentes foi relatado pelos dois grupos. O número de incidentes foi reduzido por consenso entre os dois grupos, chegando aos 17 itens da escala, os quais foram então reescritos pelos pesquisadores.

Skarlicki e Folger (1997) descobriram que o CRO foi predito pelas três formas de interação entre justiça distributiva, de procedimentos e interacional. Os dados sugerem que procedimentos justos moderam as tendências retaliatórias 
dos indivíduos, pois com altos níveis de justiça de procedimentos, as duas formas de interação, distributiva e interacional, não foram significativas. O mesmo ocorreu com a justiça interacional, porque a interação entre justiça distributiva e de procedimentos não foi significativa. O estudo desses autores aponta como único preditor de retaliação a percepção de injustiça organizacional, apresentando um modelo correlacional.

Esses resultados confirmam a tese segundo a qual, quando os supervisores mostram adequação a seus funcionários, tratando-os com dignidade e respeito, os últimos tornam-se propensos a tolerar uma combinação de pagamento injusto (justiça distributiva) e procedimentos injustos, o que poderia, em outra situação, contribuir para tendências retaliatórias. Esses dados são coerentes com os encontrados por Levinson (1965), os quais demonstram que o supervisor personifica a organização.

Os resultados obtidos por Skarlicki e Folger (1997) sugerem que os dois tipos de justiça, de procedimentos formais e de interação pessoal, podem funcionar como substitutos um do outro. O trabalho desses autores traz grandes contribuições para o desenvolvimento de estudos sobre a retaliação no trabalho, pois eles foram os precursores dessa linha de pesquisa.

Seguindo não uma ordem de importância dos estudos, mas a disposição cronológica deles encontra-se o trabalho desenvolvido por Skarlicki, Folger e Tesluk (1999), no qual consideram que os comportamentos de retaliação podem ocorrer por outras razões que não a injustiça percebida. Os autores objetivaram determinar se certos fatores de personalidade moderam a relação entre justiça e retaliação no local de trabalho e se a inclusão de variáveis de personalidade no estudo aumentaria o poder preditivo do modelo que eles estavam propondo.

Para medir a percepção de justiça, Skarlicki, Folger e Tesluk (1999) utilizaram três escalas: uma de quatro itens para a medida de justiça distributiva; uma de oito itens para a medida de justiça de procedimentos formais; e uma de nove itens para a medida de justiça interacional. Dois fatores de personalidade foram apresentados como moderadores da relação entre justiça organizacional e retaliação: estados emocionais negativos e capacidade de concordância. Esses fatores foram medidos por uma escala construída com base nos fatores de personalidade do Big Five, um teste que investiga os seguintes traços de personalidade: neuroticismo, extroversão, abertura para experiências, concordância e conscienciosidade (Saucier, 1992).

Para medir a retaliação no trabalho, Skarlicki, Folger e Tesluk (1999) utilizaram a escala de observação comportamental de Skarlicki e Folger (1997), na qual os respondentes relatam os comportamentos observados em relação ao que seus 
colegas emitiram no trabalho. Os autores justificam a metodologia de utilização da observação dos comportamentos emitidos pelos colegas de trabalho, afirmando que os indivíduos são relutantes em relatar os próprios comportamentos desviantes no trabalho, devido ao potencial que esses comportamentos apresentam para a repreensão.

Os resultados obtidos no estudo mencionado reforçam a perspectiva interacional para explicar a retaliação no trabalho. As variáveis de personalidade moderaram a relação entre justiça e comportamentos retaliatórios. Tomados em conjunto, esses resultados mostram que é um risco enquadrar os modelos comportamentais de retaliação apenas em variáveis situacionais ou variáveis disposicionais, não incluindo a interação delas.

Os dados encontrados na pesquisa de Skarlicki, Folger e Tesluk (1999) confirmam estudos prévios sobre justiça, ao mostrar que as pessoas reagem de forma diferente aos tratamentos injustos. Judge e Martocchio (1995) relatam que quando um indivíduo apresenta nível elevado de estados emocionais negativos, mostrando-se aborrecido, impaciente e raivoso, pode ser mais propenso a reagir na presença de tratamentos injustos do que aquele que tem baixo nível deles. Da mesma forma, uma pessoa com predisposição para o antagonismo e a confrontação, isto é, baixo nível de concordância, apresentará comportamentos de retaliação mais prontamente do que uma pessoa cooperativa.

No estudo desenvolvido por Townsend, Phillips e Elkins (2000), foi investigada a influência de trocas insatisfatórias entre chefia e subordinados sobre a retaliação dos empregados. Também foi analisada a contrapartida do comportamento negativo no trabalho por meio da influência de relações de troca positivas sobre o desempenho das tarefas e sobre o comportamento de cidadania organizacional. Para os autores, os empregados emitem comportamentos de reciprocidade, os quais podem ser entendidos como atos de revanche, quando percebem as situações de troca entre chefia e subordinados como insatisfatórias. Esses atos, na análise de Bies e Tripp (1996), geralmente ocorrem, quando os relacionamentos hierárquicos no ambiente de trabalho são caracterizados pela iniqüidade, seja em relação ao poder, ao status ou à influência.

Townsend, Phillips e Elkins (2000) utilizaram a medida de retaliação desenvolvida por Skarlicki e Folger (1997). Os questionários foram aplicados a uma amostra de 150 indivíduos, sendo dois grupos de estudantes de pós-graduação em Psicologia e em Administração de uma universidade pública dos Estados Unidos, que também eram trabalhadores das mais diversas áreas e ocupações. Os questionários foram distribuídos a duas classes de alunos de pós-graduação que participaram voluntariamente e obtiveram pontuações pela participação na pesquisa. 
Os resultados da pesquisa demonstraram que os supervisores geralmente atribuem maiores níveis à cidadania organizacional do que ao comportamento de retaliação em comparação aos subordinados. Além disso, confirmaram-se as hipóteses de que o comportamento de cidadania organizacional estaria fortemente correlacionado com as boas relações de troca entre chefia e subordinados. Por outro lado, o comportamento de retaliação organizacional aumenta em proporção aos relacionamentos insatisfatórios entre chefia e subordinados. Os autores, no entanto, alertam que as correlações encontradas não podem ser analisadas como relações de causalidade. Sugerem, ainda, que os dados não devem ser interpretados como se os subordinados retaliassem mais do que os superiores, pois não foi feito este tipo de análise, podendo haver uma escalação recíproca de comportamentos negativos entre superiores e subordinados.

No conjunto, apesar de os dados obtidos por Townsend, Phillips e Elkins (2000) não se basearem em uma escala de medida para investigação da percepção de justiça, seus resultados vão ao encontro dos de Skarlicki e Folger (1997), em relação à evidência empírica de que as iniqüidades percebidas no tratamento dos superiores levam a relações de troca insatisfatórias e à retaliação dos empregados.

Todos os estudos aqui mencionados têm em comum a utilização da escala desenvolvida por Skarlicki e Folger (1997), a qual se refere a uma medida comportamental de retaliação.

Com o intuito de investigar se a representação que os trabalhadores brasileiros fazem da retaliação organizacional é a mesma descrita no estudo de Skarlicki e Folger (1997) e validar uma escala para uso no Brasil, Mendonça et al. (submetido) $)^{(1)}$ desenvolveram um estudo composto por três etapas distintas.

Na primeira etapa, os itens foram levantados por meio da técnica dos incidentes críticos (Flanagan, 1954), em instituições públicas e privadas. Essa etapa possibilitou chegar à primeira versão do instrumento, que foi submetida à validação semântica em grupo composto por indivíduos com ensino médio completo, sendo efetuadas as correções que se fizeram necessárias. $\mathrm{O}$ instrumento passou pela análise de cinco juízes, todos psicólogos com experiência na área organizacional, chegando à versão final com 31 itens, dos quais 16 são os mesmos do instrumento de Skarlicki e Folger (1997).

Na segunda etapa foi desenvolvido um estudo-piloto com o objetivo de identificar e superar as dificuldades encontradas pelos indivíduos em relatar seus próprios comportamentos de retaliação. Segundo Mendonça et al. (submetido), essa dificuldade deriva do potencial para repreensões a que os trabalhadores estão sujeitos, quando admitem que reagem contra a injustiça percebida. Os 31 itens foram aplicados em uma instituição pública, utilizando-se três instrumentos 
diferentes, com estímulos específicos em cada um. O primeiro instrumento é uma medida de freqüência comportamental; o segundo, de intenção comportamental; e o terceiro possui duas escalas, sendo uma sobre a percepção, enquanto a outra investiga o julgamento que os sujeitos fazem em relação à retaliação organizacional.

Os resultados do estudo-piloto demonstraram que as pessoas não assumem que emitem comportamentos de retaliação e não admitem que têm vontade (intenção) de retaliar, mas percebem que esse tipo de comportamento acontece no contexto de trabalho em que estão atuando e julgam positivamente a emissão desses comportamentos, quando as pessoas estão sendo submetidas a situações de injustiça. Considerando esses resultados, os autores optaram pelo terceiro instrumento para realizar a validação psicométrica.

A terceira etapa do estudo foi a validação fatorial das medidas de percepção de retaliação e de atribuição de justiça acerca da retaliação. Esse instrumento foi aplicado a trabalhadores da iniciativa privada e do setor público $(n=187)$. Os 31 itens foram respondidos em duas colunas. Na primeira coluna utilizou-se uma escala de cinco pontos (variando de $1=$ nunca a $5=$ sempre), em que se pediu que os sujeitos apontassem a freqüência com que as pessoas, ao se sentirem injustiçadas, se comportam da maneira descrita nas sentenças. Nessa coluna objetivou-se investigar a percepção de retaliação. Na segunda coluna foi utilizada uma escala de cinco pontos (variando de 1 = muito injusto a 5 = justíssimo), em que se pediu que os respondentes expressassem suas opiniões pessoais e julgassem os comportamentos descritos nas frases. Essa coluna foi construída com o objetivo de investigar a atribuição de justiça ao comportamento de retaliação.

Os autores utilizaram o método dos componentes principais (eigenvalue $>2,0$ ) e estipularam o critério de carga fatorial de 0,40 , permanecendo na solução final 15 itens. Os resultados finais da análise fatorial demonstraram que apenas um fator emergiu dos dados nas duas escalas. A escala de percepção de retaliação explica 57\% da variância total e possui coeficiente de fidedignidade de 0,95. A escala que investiga a atribuição de justiça acerca da retaliação explica 36\% da variância total e possui coeficiente de fidedignidade de 0,89.

Esses resultados, assim como os de Skarlicki e Folger (1997), demonstram que a retaliação no trabalho se estrutura em um único eixo e que não está direcionada especificamente para a organização ou para as pessoas que dela fazem parte. $\mathrm{O}$ estudo desenvolvido por Mendonça et al. (submetido) é coerente com a realidade do Brasil e avança no sentido de encontrar uma medida válida para investigar a percepção e o julgamento sobre os comportamentos de retaliação emitidos no 
ambiente de trabalho. Os autores daquele estudo optaram por utilizar o instrumento de percepção e julgamento da retaliação como mediador na composição do modelo causal da atitude em relação à retaliação organizacional.

A análise da retaliação organizacional deve considerar o contexto no qual esses comportamentos são emitidos e deve, portanto, ser feita com base na interação do indivíduo com a organização. Nessa perspectiva, Mendonça e Tamayo (submetido) $^{(2)}$ desenvolveram um instrumento de medida que investiga os componentes afetivos e conativos da retaliação, a partir de cenário hipotéticoconceitual. Essa pesquisa aborda uma situação que pode ser considerada injusta no contexto organizacional e, conseqüentemente, provoca reações retaliatórias no trabalhador. A partir desse cenário, os respondentes se manifestam em relação ao sentimento de raiva e ressentimento diante da injustiça no trabalho, em que comparece o componente afetivo; e à tendência consciente para retribuir com a retaliação a tais situações, em que comparece o componente conativo. Essa medida atitudinal foi utilizada no referido estudo, por possibilitar maior compreensão da retaliação e constituir instrumento tecnicamente adequado para ser utilizado na análise de fenômenos organizacionais.

Mendonça e Tamayo (submetido) optaram por utilizar a concepção atitudinal para o estudo da retaliação, porquanto as atitudes são consideradas como antecedentes diretos do comportamento (Ajzen, 1988; Ajzen e Fishbein, 1980). Para Ros (2002), as atitudes nos ajudam a entender a realidade, a nos posicionar em face dela, a orientar nossa conduta e a justificar nossas ações. Assim, ao utilizar um modelo causal que engloba dimensões perceptivas, avaliativas, afetivas e conativas sobre a retaliação, busca-se ampliar as perspectivas desenvolvidas anteriormente e compreender esse fenômeno de maneira mais ampla.

\section{Justiça Organizacional}

Os estudos sobre retaliação apresentam como principal antecedente a percepção de justiça. O primeiro dos teóricos a apresentar grandes contribuições para os estudos relacionados à justiça foi Homans (1961). Para o autor, o homem espera receber suas recompensas de forma proporcional às relações de troca que estabelece com seus colegas de trabalho: uma relação econômica, de forma que as recompensas ou o lucro crescem de acordo com os investimentos e os custos. Seguindo esse pressuposto, outros estudos (Adams, 1965; Walster, Berscheid e Walster, 1973; Deutsch, 1975) trouxeram sua contribuição, ao analisar a justiça distributiva, que se refere à avaliação do quanto é justa determinada alocação de recursos e de recompensas direcionadas às pessoas. Entretanto a justiça distributiva não se restringe à regra única da eqüidade. De acordo com Deutsch (1975), esse modelo unidimensional da justiça é limitado para compreender os 
processos psicológicos que envolvem um fenômeno de tamanha complexidade e atribui importância especial a três princípios de justiça: da necessidade, da contribuição e da igualdade. Deutsch $(1975 ; 1985)$ defende o caráter situacional da justiça e salienta que o contexto é o melhor regulador dos diferentes sistemas de distribuição.

Considerando que a distribuição e a alocação de recursos são insuficientes para explicar a natureza da justiça organizacional em sua amplitude, surgiram outros estudos, como os de Leventhal (1980) e Thibaut e Walker (1975), que foram desenvolvidos com o objetivo de compreender os procedimentos que levam a uma determinada distribuição: a justiça dos procedimentos. Para Thibaut e Walker (1975), os indivíduos qualificam de maneiras diversas o que é justo em relação aos procedimentos de tomada de decisão. Esse tipo de justiça tem sido foco de intensos debates na literatura especializada e diz respeito à oportunidade de as pessoas expressarem suas opiniões no processo decisório e influenciar nos resultados (Thibaut e Walker, 1975).

De acordo com Leventhal (1980), a justiça processual emerge a partir de seis regras: (1) consistência das regras e normas a serem aplicadas ao longo do tempo, de forma que os mesmos critérios sejam adotados independentemente das pessoas a serem beneficiadas; (2) ausência de vieses e interesses pessoais dos indivíduos que tomam a decisão; (3) veracidade das informações dadas aos indivíduos envolvidos no processo decisório; (4) representatividade dos afetados no processo decisório, de forma que os valores e os interesses de todos sejam considerados; (5) ética no que se refere aos valores morais; (6) possibilidade de correção e modificação das decisões injustas. O mesmo autor defende ainda que essas regras devem ser consideradas nos procedimentos organizacionais, porquanto, se estes levarem a um resultado não desejado, há maior tendência de os indivíduos responderem destrutivamente, provocando conseqüências que abrangerão todo o processo organizacional.

Os estudos sobre o impacto da justiça sobre o funcionamento organizacional mostram que quando os empregados percebem os procedimentos como justos ficam menos preocupados com aqueles injustos (Cropanzano e Folger, 1989; Barling e Phillips, 1993). Além dos procedimentos formais, é igualmente relevante a forma como eles são implementados (Bies, 1987). Para Moorman (1991), a justiça interacional é mais importante do que os procedimentos formais para determinar o comportamento dos empregados nas organizações. O conceito de justiça interacional foi introduzido por Bies e Moag (1986) como um dos três segmentos da justiça organizacional e refere-se às concepções da pessoa sobre a "qualidade do tratamento interpessoal recebido nos procedimentos organizacionais” (Bies e Moag, 1986, p. 44). 
Os estudos sobre justiça organizacional têm demonstrado o poder heurístico desse construto para a compreensão de atitudes e comportamentos organizacionais, reforçando a importância de que os pesquisadores da área organizacional se dediquem a investigar os antecedentes e os conseqüentes desse fenômeno com o intuito de promover a eficácia nas organizações de trabalho.

Nessa perspectiva, o presente estudo foi desenvolvido com o objetivo de testar um modelo teórico de estimativa da atitude em relação à retaliação, por meio da técnica estatística modelagem de equação estrutural (SEM), visando a analisar de que modo a justiça organizacional, como variável antecedente, explica a variável-critério de atitude em relação à retaliação. Pretende-se comprovar que, a partir do momento em que se sente injustiçado e percebe a retaliação no contexto de trabalho, julgando positivamente a emissão desses comportamentos, conseqüentemente o trabalhador sente indignação e descontentamento com a injustiça e apresenta tendência consciente para agir de maneira retaliatória. Configura-se, portanto, o modelo hipotético-conceitual deste estudo.

\section{MÉTOdo}

\section{Participantes}

Participaram do presente estudo 313 trabalhadores de uma instituição pública, cuja idade foi investigada por meio de categorias que variaram de 1 (18 a 25 anos) a 9 (61 a 65 anos) e da faixa média das idades, entre 31 e 40 anos $(37,4 \%)$. Do total, $62,3 \%$ são do sexo feminino e 50,8\% possuem nível superior de escolaridade.

\section{Procedimentos}

A coleta de dados relativa às variáveis definidas nesta pesquisa foi efetuada por meio de questionário que contém as seguintes escalas: percepção de justiça organizacional (Mendonça et al., 2003); percepção e julgamento da retaliação organizacional (Mendonça et al., submetido); medida de atitude em relação à retaliação organizacional (Mendonça e Tamayo, submetido).

Para a aplicação do questionário solicitou-se a autorização dos diretores de uma instituição pública, ficando garantido seu anonimato. Os instrumentos foram administrados individualmente no próprio local de trabalho. Foram distribuídos 761 questionários juntamente com um envelope para serem devolvidos lacrados e recolhidos em horários previamente estabelecidos; o total de questionários 
aproveitáveis na devolução foi de 41,2\%. Foi esclarecido aos participantes o caráter estritamente acadêmico da pesquisa e a segurança do sigilo em relação à emissão das respostas.

\section{Resultados e Discussão}

Os dados foram analisados por meio da técnica de modelagem de equação estrutural (SEM), utilizando o programa EQS 5.5 para Windows (Bentler, 1995). Nesse tipo de análise devem ser considerados dois conjuntos de resultados (Hu, Bentler e Kano, 1992): a adequação da estrutura fatorial hipotetizada e a magnitude das relações entre as variáveis envolvidas nessa estrutura. A adequação da estrutura deve levar em conta vários indicadores, entre os quais se destacam o $\chi^{2}$ calculado, a razão entre o valor de $\chi^{2}$ e os seus graus de liberdade, $\chi^{2} / g l$ (Watkins, 1989); o Comparative Fit Index - CFI (Bentler, 1995); e o Root Mean Square Error of Approximation - RMSEA (Browne e Cudeck, 1993). Considerase o modelo adequado, quando o valor de $\chi^{2}$ não é significativo, pois indica que não há diferença entre a estrutura teórica e a subjacente aos dados analisados (Bentler e Bonett, 1980); ou quando a razão $\chi^{2} / g l$ for inferior a 3 e o CFI apresentar coeficiente igual ou maior do que 0,90 (Kline, 1994); ou ainda quando forem obtidos valores de RMSEA inferiores a 0,10 (Browne e Cudeck, 1993). A estimativa das relações entre as variáveis da estrutura proposta foi realizada sobre a matriz de covariâncias entre as variáveis, utilizando-se o método da Máxima Verossimilhança Escalonada.

Quanto à estrutura prevista na investigação da atitude em relação à retaliação, o modelo analisado obteve excelente solução. Todos os índices de ajuste (FIT) revelam que o modelo é adequado para explicar as relações entre as variáveis. Os resultados apresentam $\chi^{2}$ não significativo, com os seguintes índices de adequação: $\chi^{2}(10, \mathrm{~N}=313)=18,57 ; \chi^{2} / \mathrm{gl}=1,86$; CFI = 0,98; GFI = 0,97; e RMSEA $=0,06(0,007-0,096)$. Assim, os coeficientes foram estatisticamente significativos, indicando adequação dos pressupostos teóricos e confirmando a adequação do modelo.

Quanto à estimativa das relações entre as variáveis do modelo, os resultados (Figura 1) indicam que o modelo teórico proposto é adequado e explica $81 \%$ da retaliação. Como pode ser constatado, a justiça organizacional é constituída pelas dimensões de justiça distributiva $(\lambda=0,56 ; \mathrm{p}<0,05)$, justiça de procedimentos interacionais $(\lambda=0,79 ; \mathrm{p}<0,05)$ e justiça de procedimentos formais $(\lambda=0,86 ; \mathrm{p}$ $<0,05)$. Este construto estima $(\gamma=-0,47 ; p<0,05)$ a percepção e o julgamento da retaliação, que é um construto composto pela percepção da retaliação $(\lambda=$ 
0,43; $\mathrm{p}<0,05)$ e pelo julgamento acerca dos comportamentos de retaliação organizacional $(\lambda=0,28 ; \mathrm{p}<0,05)$. Seguindo a trajetória das variáveis prevista para este modelo, a percepção e o julgamento da retaliação estimam $(\gamma=0,90$; $p$ $<0,05)$ a atitude em relação à retaliação, que é um construto composto pelos componentes afetivo $(\lambda=0,56 ; \mathrm{p}<0,05)$ e conativo $(\lambda=0,67 ; \mathrm{p}<0,05)$.

\section{Figura 1: Resultado da Equação Estrutural Aplicada ao Modelo Atitudinal da Retaliação Organizacional}

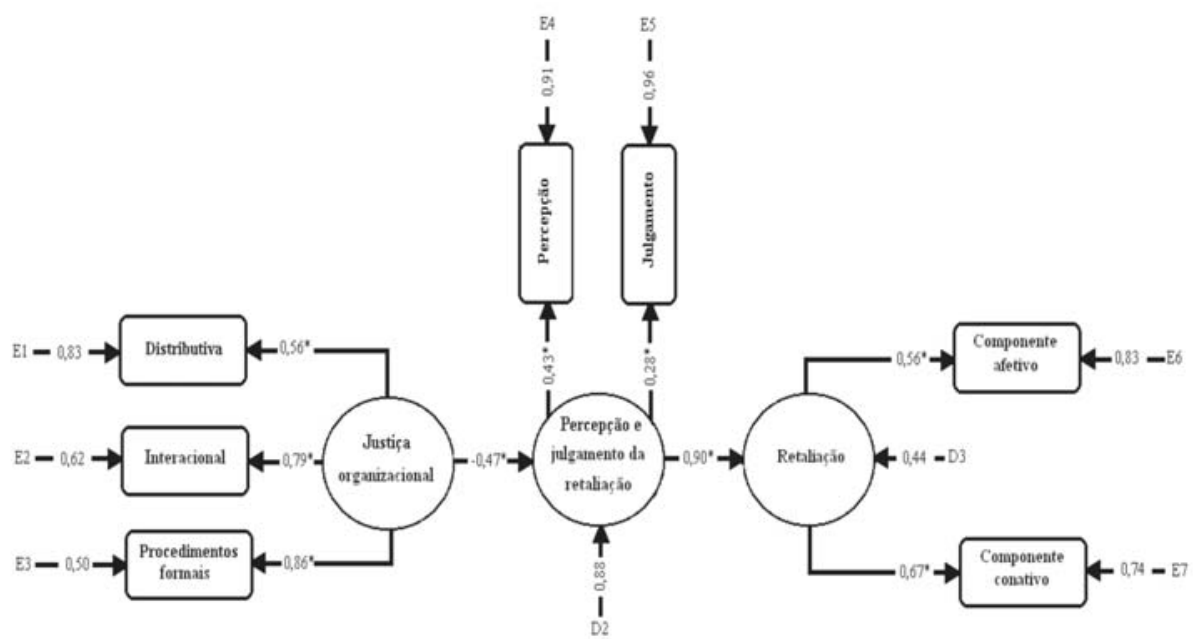

Nota: $\mathrm{p}^{*}<$ 0,01; E1-E7 = erro de medida das variáveis observáveis; D2-D3 = distúrbios dos construtos.

Assim, a estrutura das relações que constituem este modelo foi significativa, confirmando a direção das relações previstas e atendendo aos objetivos do estudo. Nesse sentido, a percepção de justiça organizacional pode ser considerada um construto tridimensional, que engloba os componentes distributivos, processuais e interacionais. De fato, quanto maior for a percepção de justiça organizacional, menor será a percepção de retaliação e o julgamento de que a emissão desses comportamentos é justa. Além disso, as análises confirmam a estrutura bidimensional da variável perceptiva e avaliativa sobre a retaliação organizacional. No que diz respeito à atitude em relação à retaliação, confirma-se a estrutura bifatorial da medida, englobando o componente afetivo e conativo. Verifica-se também que a percepção e o julgamento da retaliação contribuem para a estimativa da retaliação. Esses resultados permitem concluir que a retaliação e a justiça organizacional exercem relação de causalidade com a atitude do trabalhador diante da retaliação. 


\section{Conclusão}

\section{Análise das Relações Obtidas}

Contrariamente à perspectiva prévia sobre retaliação organizacional, o presente estudo investiga esse construto sob uma perspectiva atitudinal, concebendo-o como fenômeno composto por dimensões afetivas, conativas, perceptivas e avaliativas. No que se refere ao teste empírico do modelo proposto, obteve-se excelente resultado. Todos os índices de ajuste revelam adequação do modelo aos dados, explicando $81 \%$ da variabilidade.

Nesse sentido, quanto menos percebe o contexto organizacional como justo e quanto mais percebe a retaliação e julga positivamente a emissão desses comportamentos, mais o trabalhador demonstra atitude favorável à retaliação. Fica comprovado, portanto, que a atitude em relação à retaliação organizacional é causada sobretudo pelas variáveis contextuais, porque, diante do elevado índice de variabilidade obtido, resta muito pouco espaço para explicações de outra natureza.

Os resultados trazem evidências empíricas acerca da multideterminação da retaliação, proporcionando visão mais ampla acerca desse fenômeno organizacional. Diferentemente dos trabalhos encontrados na literatura sobre a retaliação (Skarlicki e Folger, 1997; Skarlicki, Folger e Tesluk., 1999; Townsend, Phillips e Elkins, 2000), o presente estudo não aborda o comportamento propriamente dito, mas as dimensões conativas e afetivas, compondo um modelo atitudinal para a retaliação.

Neste estudo, a retaliação aglutina dimensões perceptivas, avaliativas, afetivas e conativas. Em conjunto, essas dimensões envolvem a indignação com a injustiça, o ressentimento, a raiva, a severidade da perda, o merecimento da retribuição, a conduta imprópria da chefia e a tendência consciente para reagir com a retaliação. Esses componentes caracterizam a atitude em relação à retaliação e têm como antecedentes a percepção de injustiça e as dimensões perceptivas e avaliativas acerca da retaliação. Essas variáveis podem ser caracterizadas como focos que levam a uma atitude positiva do trabalhador em relação à retaliação. A Figura 2 representa graficamente a multideterminação da retaliação. 
Figura 2: Focos da Retaliação Organizacional.

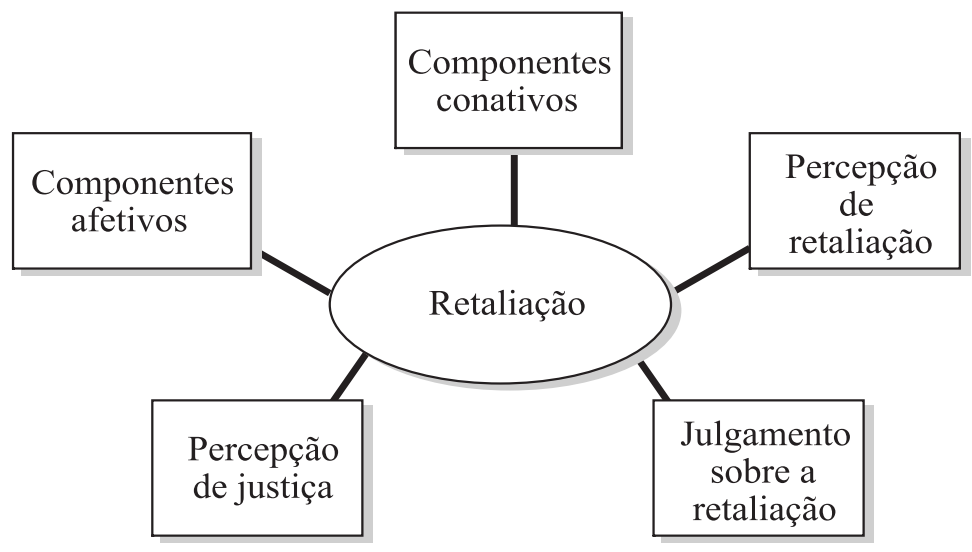

Tomados em conjunto, os dados apontam o contexto organizacional como o principal responsável pela atitude dos trabalhadores em relação à retaliação. Essas predisposições comportamentais emergem em resposta às injustiças e ganham força com a percepção e o julgamento positivo da retaliação. O conhecimento das variáveis preditoras da atitude em relação à retaliação constitui ferramenta importante para a melhoria do desempenho e das condições de trabalho. Assim, o modelo testado neste estudo é útil para distintos contextos organizacionais, pois traz maior compreensão sobre as variáveis antecedentes que levam o trabalhador a emitir comportamentos negativos no ambiente de trabalho, podendo subsidiar planos de intervenção que visem ao estabelecimento de critérios pautados na justiça organizacional.

\section{Notas}

${ }^{1}$ MENDONÇA, H.; FLAUZINO, D.P.; TAMAYO, A.; PAZ, M.G.T. Percepção e julgamento da retaliação organizacional: construção e validação das escalas. Artigo enviado para publicação.

${ }^{2}$ MENDONÇA, H.; TAMAYO, A. Construção e validação de um instrumento para a medida de atitude em relação à retaliação organizacional (MARO). Artigo enviado para publicação.

Artigo recebido em 05.08.2003. Aprovado em 10.02.2004. 


\section{ReferênCIAs Bibliográficas}

ADAMS, J. S.

Inequity in social exchange. In: BERKOWITZ, L. (Org.) Advances in experimental social psychology. v. 2 . New York: Academic, 1965.

\section{AJZEN, I.;}

FISHBEIN, $M$.

Understanding attitude and predicting social behavior. Englewood Cliffs: Prentice-Hall, 1980.

BARLING, J.;

PHILLIPS, $M$.

Interactional, formal and distributive justice in the workplace: an exploratory study. Journal of Psychology, v. 127, n. 6, p. 649-656, 1993.

BENTLER, P. M.

EQS: structural equations program manual. Encino: Multivariate Software, 1995.

BENTLER, P. M.;

BONETT, D. G.

Significance tests and goodness of fit in the analysis of covariance structures. Psychological Bulletin, v. 88, p. 588-606, 1980.

\section{BIES, R. J.}

The predicament of injustice: the management of moral outrage. In: CUMMINGS, L.L.; STAW, B.M. (Org.) Research in organizational behavior. v. 9. Greenwich: JAI, 1987.
BIES, R. J.;

MOAG, J. S.

Interactional justice: communication criteria of fairness. In: LEWICKI, R.J.; SHEPPARD, B.H.; BAZERMAN, M.H. (Org.) Research on negotiation in organizations. Greenwich: JAI, 1986.

BIES, R. J.;

TRIPP, T. M.

Beyond distrust: "getting even" and the need for revenge. In: KRAMER, R.M.; TYLER, T.R. (Ed.) Trust in organizations. Thousand Oaks: Sage, 1996.

BORGES-ANDRADE, J. E.;

AFANASIEFF, R. S.;

SILVA, M. S.

Mensuração de comprometimento organizacional em instituições públicas. In: REUNIÃO ANUAL DE PSICOLOGIA, 19., 1989, Ribeirão Preto. Anais... Ribeirão Preto: Sociedade Brasileira de Psicologia, 1989.

BROWNE, M. W.;

CUDECK, R.

Alternative ways of assessing model fit. In: BOLLEN, K.A.; LONG, L.S. (Org.) Testing structural equation models. Newbury Park: Sage, 1993. 
CROPANZANO R.;

FOLGER, R.

Referent cognitions and task decisions autonomy: beyond equity theory. Journal of Applied Psychology, v. 74, n. 2, p. 293-299, 1989.

\section{DEUTSCH, M.}

Distributive justice: a socialpsychological perspective. New Haven: Yale University, 1985.

Equity, equality, and need. What determines which value will be used as the bases of distributive justice? Journal of Social Issues. v. 31, n. 3, p. 137-149, 1975.

FLANAGAN, J. C.

The critical incident technique. Psychological Bulletin, v. 51, p.327358, 1954.

HOMANS, G. C.

Social behavior: its elementary forms. New York: Harcourt, Brace \& World, 1961.

HOUAISS, A.;

VILLAR, M. S.

Dicionário Houaiss da língua portuguesa. Rio de Janeiro: Objetiva, 2001.

HU, L.T.;

BENTLER, P. M.;

KANO, Y.

Can test statistics in covariance structure analysis be trusted? Psychological Bulletin, v. 112, p. 351362, 1992.
JUDGE, T.A.;

MARTOCCHIO, J. J.

The role of fairness orientation and supervisor attributions in absence of disciplinary decisions. Journal of Business and Psychology, v. 10, p. 115-137, 1995.

KLINE, P.

An easy guide to factor analysis. London: Routledge, 1994.

\section{LEVENTHAL, G. S.}

What should be done with equity theory? In: GERGEN, K.J.; GREENBERG, J.; WEISS, R.H. (Org.) Social exchange: advances in theory and research. New York: Plenum, 1980.

\section{LEVINSON, $\mathrm{H}$.}

Reciprocation: the relationship between man and the organization. Administrative Science Quarterly, v. 9, p. 370-390, 1965.

MENDONÇA, H.;

PEREIRA, C.;

TAMAYO, A.; PAZ, M. G. T.

Validação fatorial de uma escala de percepção de justiça organizacional. Estudos Saúde e Vida, v. 30, n. 1, p.111-130, 2003.

\section{MOORMAN, R. H.}

Relationship between organizational justice and organizational citizenship behaviors: do fairness perceptions influence employee citizenship? Journal of Applied Psychology, v. 76, n. 6, p. 845-855, 1991. 
MOWDAY, R.T.;

STEERS, R. M.;

PORTER, L.W.

The measurement of organizational commitment. Journal of Vocational

Behavior, v. 14, p. 224-247, 1979.

ORGAN, D.W.;

MOORMAN, R.H.

Fairness and organizational citizenship behavior: what are the connections? Social Justice Research, v. 6, p. 5-18, 1993.

\section{ROBINSON, S. L.;}

\section{BENNETT, R.I.}

A typology of deviant workplace behaviors: a multidimensional scaling study. Academy of Management Journal, v. 38, n. 2, p. 555-572, 1995.

\section{ROS, $\mathrm{M}$.}

Valores, actitudes y comportamiento: una nueva visita a un tema clásico. In: ROS, M.; GOUVEIA, V.V. (Org.). Psicología social de los valores humanos: desarrollos teóricos, metodológicos y aplicados. Madrid: Biblioteca Nueva, 2002.

\section{SAUCIER, G.}

Benchmarks: integrating affective and interpersonal circles with the Big Five personality factors. Journal of Personality and Social Psychology, v. 62, p. 1025-1035, 1992.

\section{SIQUEIRA, M. M. M.}

Antecedentes do comportamento de cidadania organizacional: a análise de um modelo pós-cognitivo. Brasília, 1995. Tese (Doutorado em Psicologia)
- Instituto de Psicologia, Universidade de Brasília.

SKARLICKI, D. P.;

FOLGER, R.

Retaliation in the workplace: the roles of distributive, procedural, and interactional justice. Journal of Applied Psychology, v. 82, n. 3, p. 434443, 1997.

SKARLICKI, D. P.;

FOLGER R.;

TESLUK, $P$.

Personality as a moderator in the relationship between fairness and retaliation. Academy of Management Journal, v. 42, p. 100-108, 1999.

TAMAYO,A.

Valores organizacionais: sua relação com satisfação no trabalho, cidadania organizacional e comprometimento afetivo. Revista de Administração, v. 33, p. 56-63, 1998.

TAMAYO, A.;

SOUZA, M. G. S.;

VILAR, S. L.;

RAMOS, J. L.;

ALBERNAZ, J.V.;

FERREIRA, N.P.

Prioridades axiológicas e comprometimento organizacional. Psicologia: Teoria e Pesquisa, v. 17, n. 1, p. 27-35, 2001.

THIBAUT, J.W.; WALKER, L.

Procedural justice: a psychological analyses. New York: Erlbaum/ Hillsdale, 1975. 
TOWNSEND, J.;

PHILLIPS, J.S.;

ELKINS, T.J.

Employee retaliation: the neglected consequences of poor leader-member exchange relations. Journal of Occupational Health Psychology, v. 38, n. 4, p. 457-463, 2000.

WALSTER, E.;

BERSCHEID, E.;

WALSTER, G.

New directions in equity research. Journal of Personality and Social Psychology, v. 25, p. 151-176, 1973.

\section{WATKINS, D.}

The role of confirmatory factor analysis in cross-cultural research. International Journal of Psychology, v. 24, p. 685-701, 1989. 